\title{
Analysis of Enhanced Recovery after Surgery Applications in Patients Who Received Surgical Intervention
}

\author{
Selda Rizalar ${ }^{*}$, Sacide Yildizeli Topcu ${ }^{2}$ \\ ${ }^{1}$ Department of Nursing, Health Science Faculty, Istanbul Medipol University, Istanbul, Turkey \\ ${ }^{2}$ Nursing Department, Faculty of Health Science, Trakya University, Edirne, Turkey \\ Email: srizalar@medipol.edu.tr, ${ }^{*}$ srizalar@omu.edu.tr, sacideyildizeli@yahoo.com
}

Received 1 October 2015; accepted 16 October 2015; published 21 October 2015

Copyright (C) 2015 by authors and OALib.

This work is licensed under the Creative Commons Attribution International License (CC BY).

http://creativecommons.org/licenses/by/4.0/

(c) (i) Open Access

\begin{abstract}
Background \& Objectives: Accelerated recovery approaches decrease the stress response, improve the functions of organs and thus shorten the recovery process postoperatively. Nurses, as a member of health care team, have the key role in these applications. This research was carried out with the aim of analyzing the ERAS methods which applied to the patients in surgical clinics. Method: A cross-sectional descriptive study was conducted in 2013 to include 194 patients who underwent a surgical intervention. Data were collected using a researcher-made questionnaire and statistically evaluated using percentage, chi-square test and correlation analysis. Results: It was found that almost all of the patients got information about operation in preoperative period. According to our study, mostly general anesthesia was applied (87.6\% of the patients); fasting durations (27.3 \pm $20.2 \mathrm{hr}$ for liquid and $38.2 \pm 22.8 \mathrm{hr}$ for solid food) and first mobilization durations (33.6 $\pm 19.5 \mathrm{hr})$ were long and approximately in half of the patients total pain control couldn't be achieved. It was detected that intravenous catheters were often used whereas urinary catheter or nasogastric tube was rarely used. As the first mobilization time extended, length of stay in the hospital prolonged postoperatively. Conclusion: Based on the study findings, it was concluded that ERAS programs were applied partially.
\end{abstract}

\section{Keywords}

Accelerated Recovery Programs, Enhanced Recovery after Surgery, Fast Track Surgery, Nursing Care, Postoperative Care

Subject Areas: Nursing

${ }^{*}$ Corresponding author.

How to cite this paper: Rizalar, S. and Topcu, S.Y. (2015) Analysis of Enhanced Recovery after Surgery Applications in Patients Who Received Surgical Intervention. Open Access Library Journal, 2: e2010. http://dx.doi.org/10.4236/oalib.1102010 


\section{Introduction}

Surgical stress response, which might cause changes in organ functions, is one of the important factors experienced by all of the patients who underwent surgical intervention. The side effects which can be seen in patients after surgery include gastrointestinal malfunction and ileus, hypoxemia, exhaustion, loss of muscular tissue, perceptual disorder as well as cardiopulmonary, infective and thromboembolic complications. Any one of these conditions may delay the hospital discharge, prolong recovery period and in the long term may affect prognosis negatively way [1] [2]. However in recent years, the changes and the developments in surgical techniques and perioperative administrative applications established better control of stress response for patients intra- and postoperatively and improved care results [2] [3].

Nowadays the accentuated point for the improvement of postoperative care results is the term of "enhanced recovery after surgery (ERAS)" and it is also called as "fast track surgery" [2]. The enhanced recovery after surgery is the compound of various methods used in the care of patients who underwent an elective operation [1]. The concept of enhanced recovery after surgery involves using various strategies to facilitate better conditions for surgery and recovery in an effort to achieve faster discharge from hospital and more rapid resumption of normal activities after both major and minor surgical procedures, without an increase in complications or readmissions [4]-[6].

Patient education, optimising organ function before surgery, improved anaesthetic and postoperative analgesic techniques and better understanding of perioperative care principles with early oral feeding and ambulation, evidence based decision regarding the usage of traditional applications have resulted in enhanced postoperative recovery [1] [2] [4]-[7]. The main purpose of this integrated approach is to reduce psychological and physiological stresses associated with surgical illness, in order to reduce tissue catabolism [4]-[6].

Enhanced recovery approaches decrease the stress response, improve organ functions and thus shorten the recovery duration [4]-[6]. In the application process the nurses play a key in order for these programs, which demand multidisciplinary and coordinated effort, to be successful. Surgical nursing involves patient care applications including pre-, intra- and postoperative care of the patient to be operated. Nurses' role in preparing the patient for operation notwithstanding the sort or type of the operation and preventing any complication in intraand postoperative care is also important. It is stated that according to studies carried out in various countries proofs supporting the accelerated recovery approaches are increasing gradually [3] [8]-[10]. This study was carried out with the aim of analyzing the accelerated recovery methods after surgery, which was applied to the patients in clinics and the effects of these methods on patients.

\section{Methods}

\subsection{Participants}

The population of the research was formed by the patients who underwent an operation in general surgery, orthopedics, urology, gynecology, cardiovascular surgery clinics of Ondokuz Mayıs University Health Research and Application Center. No sampling method was used in determining the population. All of the patients staying in these clinics were paid a visit and those who had a planned operation story, were between 18 - 65 years, could speak Turkish, did not have any problem preventing the communication and agreed to participate in the research were included in the sample. Study sample were consisted of 194 patients.

\subsection{Measurements and Intervention}

Data Collection Form, which was formed by the researchers by using the references in the literature regarding the subject [1]-[3] [7] [11]-[15] was used in Data Collection. The Data Collection Form consists of two parts. First part contains information about patient's socio-demographic attributes and health history characteristics. The second part includes information regarding to the ERAS methods. They include information about preoperative and postoperative fasting durations, first mobilization time, pain relief interventions, anesthesia method, usage of tubes, drains and cathetersand length of stay at hospital. The researchers acquired the data by dual conversation with the patients and from Nurse Inspection Form. The data about socio-demographic attributes was acquired from the patients themselves, data regarding the tube drain usage was obtained by observation and the data about the usage of analgesics was acquired from Nurse Inspection Form, then they were registered in data collection form. This research was carried out between February 1, 2013-May 31, 2013 with the patients who 
underwent an operation in Ondokuz Mayis University Health Research and Application Center. The process of data collection took 30 minutes and it was performed in patient's room.

Before starting the research a written approval was obtained from Ondokuz Mayıs University Health Research and Application Centerand Ondokuz Mayıs University Clinical Researches Ethical Committee (OMUKAEK2012/139). Before starting the study the patients who were planned to be included in the research were informed about the research. Informed consent was obtained from patients verbally and in writing by using the Informed Consent Form. In the research only the patients who were willing to participate were included in the sampling.

\subsection{Data Analysis}

The data collected by the researchers was analyzed by using SPSS for Windows, version 16.0 (SPSS Inc., Chicago, Il, USA). In the evaluation of data percentage, mean \pm standard deviation, chi-square test and correlation analysis were used. Chi-square test was used to analyse categorical data. Correlation analysis was used to describe the degree of relationship between variables. $\mathrm{p}<0.05$ was considered statistically significant.

\section{Results}

The age of the patients included in the study was $49.73 \pm 17.70$. It was found out that $60.8 \%$ of the patients were female and $53.1 \%$ of the patients were primary school graduate. It was found that $49 \%$ of the patients were general surgery patients; patients stayed at the hospital $8.19 \pm 4.51$ days on average and they were discharged from the hospital after surgery in $5.47 \pm 3.23$ days on average (Table 1 ).

It was detected that all of the patients waited hungry before the operation, in $65.5 \%$ of the patients hungry waiting duration was from 24:00 until the morning, after the operation patients were mobilized in average 33.67 \pm 19.53 hours later, the time until the first postoperative fluid intake was in average $27.37 \pm 20.23$ hours, the time until the first solid intake was in average $38.21 \pm 22.86$ hours (Table 1 ).

It was found that in the preoperative period $93.8 \%$ of the patients obtained information about the operation from medical doctors and $91.8 \%$ of the patients from nurses; $93.3 \%$ of the nurses informed the patients by

Table 1. The range of patients' informative characteristics $(\mathrm{N}=196)$.

\begin{tabular}{lcc}
\hline Informative characteristics & Frequency & Percentage (\%) \\
\hline Gender & 118 & 60.8 \\
$\quad$ Female & 76 & 39.2 \\
$\quad$ Male & & 9.8 \\
Education level & 19 & 13.9 \\
$\quad$ Illiterate & 27 & 53.1 \\
$\quad$ Literate & 103 & 17 \\
$\quad$ Primary & 33 & 6.2 \\
$\quad$ High school & 12 & 49.0 \\
$\quad$ University & & 18.0 \\
Department: & 95 & 17.5 \\
$\quad$ General surgery & 35 & 10.3 \\
$\quad$ Orthopedics & 34 & 5.2 \\
$\quad$ Gynecology & 20 & Min - max \\
$\quad$ Cardiogy & 10 & $18-65$ \\
$\quad$ Mean \pm SD & $3-30$ \\
\hline Age & $49.73 \pm 17.70$ & $2-23$ \\
Total number of hospitalization days & $8.19 \pm 4.51$ & $6-72$ \\
Number of hospitalization days after operation & $5.47 \pm 3.23$ & $1-72$ \\
First mobilization duration (hours) & $33.67 \pm 19.53$ & $3-96$ \\
First liquid food intake duration (hours) & $27.37 \pm 20.23$ & $38.21 \pm 22.86$ \\
First solid food intake duration (hours) & & \\
\hline
\end{tabular}


talking to them, $98.5 \%$ of the nurses help the patients dress for the operation and $99 \%$ of the nurses help the patients take off their belongings such as accessories or prosthesis, $79.4 \%$ of the nurses taught the preoperative breathing and coughing exercises, and $79.9 \%$ of the nurses taught extremity exercise (Table 2).

It was determined that $84.5 \%$ of the patients took liquids through vascular access, $14.9 \%$ of the patients had foley catheter, $6.2 \%$ of the patients were applied nasogastric tube and $87.6 \%$ of the patients received general anesthesia (Table 3). In the non-pharmacological pain management, $2.1 \%$ of the patients were applied massage, $4.1 \%$ of the patients received applications of distraction. It was found statistically significant that effective pain control was provided in $91.1 \%$ of the patients who took Pethidine, $91.1 \%$ of the patients who took combined analgesics (Pethidine and NSAI), 65.3\% of the patients who took Tramadol, 62.2\% of the patients who took NSAI drugs and $54.9 \%$ of the patients who took Paracetamol $\left(x^{2}=45.240, p<0.000\right.$; Table 4).

Postoperatively, $38.8 \%$ of the patients on the first day, $28.1 \%$ on the second day, $11.9 \%$ on the third day were mobilized. When examining the relationship between first mobilization and duration of hospitalization, it was found that the longer the patients' first mobilization time is, the longer patients' stay in the hospital after the operation gets $(r=0.202, p=0.010$; Table 5$)$.

Table 2. The range of the applications performed by the nurses in patient training in preoperative period $(\mathrm{N}=196)$.

\begin{tabular}{cc}
\hline Nursing applications & Frequency percentage (\%) \\
\hline Relieving patients by talking (providing psychological support) & $18,193.3$ \\
Dressing the patients & $19,198.5$ \\
Taking off patients' accessories and prosthesis & $19,299.0$ \\
Teaching the patients deep breathing coughing exercises & $15,479.4$ \\
Teaching the patients extremity exercises & $15,579.9$ \\
\hline
\end{tabular}

Table 3. Catheter usage, general anesthesia receiving and enema application situations of the patients.

\begin{tabular}{cccc}
\hline Applications & Yes F P(\%) & No F P(\%) & Total F P(\%) \\
\hline Infusion through IV access & $16,484.5$ & 3015.5 & $194,100.0$ \\
NGT & 126.2 & 1893.8 & $194,100.0$ \\
Foley catheter & 2914.9 & $16,585.1$ & $194,100.0$ \\
General anesthesia & $17,087.6$ & 2412.3 & $194,100.0$ \\
Preoperative enema & 8543.8 & $10,956.2$ & $194,100.0$ \\
\hline
\end{tabular}

F: Frequency; P: Percentage (\%).

Table 4. Patients' pain management situations according to the analgesics they take.

\begin{tabular}{|c|c|c|c|c|c|}
\hline \multirow{2}{*}{$\begin{array}{l}\text { Pain management } \\
\text { situation }\end{array}$} & \multicolumn{5}{|c|}{ Type of analgesics } \\
\hline & Pethidin F P(\%) & NSAİ F P(\%) & Tramadol F P(\%) & Parasetamol F P(\%) & Combined (P + NSAİ) F P(\%) \\
\hline Provided & 5991.18 & 7962.20 & 1765.38 & 3954.92 & 5991.18 \\
\hline Partly provided & 46.25 & 4233.07 & 830.76 & 2332.39 & 46.25 \\
\hline Not provided & 11.56 & 64.72 & 13.84 & 912.67 & 11.56 \\
\hline Total & $64,100.0$ & $127,100.0$ & $26,100.0$ & $71,100.0$ & $64,100.0$ \\
\hline$x^{2}$ & 45.240 & 5.388 & 0.942 & 3.839 & 45.240 \\
\hline$P$ & $0.000^{*}$ & 0.068 & 0.624 & 0.147 & $0.000^{*}$ \\
\hline
\end{tabular}

${ }^{*} \mathrm{p}<0.05$. 
Table 5. First mobilization duration and length of stay hospital $(\mathrm{N}=196)$.

\begin{tabular}{cccc}
\hline & Min - max & Mean \pm SD & r; p \\
\hline First mobilization duration (hour) & $6-72$ & $33.67 \pm 19.53$ & $0.202 ; 0.010^{*}$ \\
Length of stay hospital (day) & $3-30$ & $8.33 \pm 4.60$ & \\
\hline
\end{tabular}
${ }^{*} \mathrm{p}<0.05$.

\section{Discussion}

Enhanced recovery is an evidence based model of care that results in patients who recover faster from major surgery. It involves a number of clinical companents delivered throughout the interventions of care. Enhanced recovery principles have been successfully applied across many elective surgical pathways such as breast, colorectal, gynaecology, urology, musculoskeletal, an aesthetics and it is currently being adopted across many more surgical specialities.

Preoperative patient training, which is the first component of the enhanced recovery, reduces anxiety and helps copping with stress, and generally improves postoperative recovery. It was shown that preoperative training efforts, which seem relatively simple, corrects the misunderstanding of patients' and increases patients' postoperative performance [2] [3]. In our study it was found that patient training was highly performed by the nurses and doctors. And it was also detected that nurses highly played their role of giving patients psychological support.

In decreasing stress response resulting from a surgical intervention it plays an important role to use an adequate anesthesia method and analgesics as well as to optimize the patient's health in the pre-operative period and to remove the inabilities. In this process patient is evaluated before the operation regarding the risk factors such as postoperative organ dysfunction and malnutrition, which extend the surgical stress response and increase the risk of any complication. Anesthesia agents, which operate in a short time, are more effective than the ones, which operate in a long time, because they allow for an enhanced recovery in the early post-operative period. And that enables the patient to participate actively in the recovery process. Different studies showed that in surgical patients, local anesthesia and analgesia especially the nerve block provide a range of benefits including improving gastrointestinal and respiratory functions, decreasing cardiovascular problems and establishing a highest level pain management. It provides a significant decrease in the stress response to surgery to maintain the epidural analgesia with local analgesics for 24 - 72 hours after the epidural anesthesia [2] [3]. It was found that only in a small group of patients (12\%), who took part in our study, spinal or epidural anesthesia was applied. In enhanced recovery programs a multimodal balanced analgesic approach is taken as a basis.

It was found out in our study that in $58.2 \%$ of all of the patients total pain management was achieved. The analgesics, which can primarily be used after the operation, are non-opioids (acetaminophen and nonsteroidal anti-inflammatory drugs [NSAID]), local anesthetics and opioids. It was determined that NSAIDs and Paracetamol are the most frequently used analgesics in our study. Multimodal analgesics approach is based on the principle of combination of agents, which provides better pain management than the usage of just one [2] [7] [11]. In our study, it was detected that in $91.1 \%$ of the patients, who received analgesics as Petidine and NSAIDs combination, the total pain management was achieved. It was observed that in patients, who took Petidine and, who received combined analgesics for pain management, in a statically significant way a more affective pain management was achieved than in patients who took other medicines. It was an expected finding that Petidine, which is an opoid, was in a statistically significant way, more affective on pain management than other medicines. However, narcotics have undesirable effects and they should be used caution. For more effective pain management, pharmacological and non-pharmacological methods should be used together. In our study it was also detected that the usage of non-pharmacological methods regarding the pain management in patients who were in the postoperative period was at a very low level (in $2.1 \%$ massage, in $4.1 \%$ distraction).

Another important component in the enhanced recovery is the early feeding and ambulation of the patients. In our study, it was found out that all of the patients waited hungry before the operation, the fasting time was from midnight until morning in most of the patients and in some of them this time of waiting could extend till noon. It is stated in Dolgun et al.'s study that the patients did not get solid food for 13.5 hours and liquid food for 12.5 hours before the operation. It was stated that $30.3 \%$ of patients felt hungry and $47.6 \%$ of them felt thirsty $(n=69)$ while undergoing the operation [16]. According to the suggestions related to the limitation of pre-operative 
hunger it is sufficient to cease the solid food six hours and the clear liquids two hours before the operation [13] [16] [17]. It was found out that the average time until the first liquid intake after the operation was $27.37 \pm 20.23$ hours and the time until the first solid food intake after the operation was $38.21 \pm 22.86$ hours. When asked about the effects of waiting hungry, most of the patients stated that the duration of hungry waiting before the operation was long and irritating. There are plenty of studies showing that the approach of early oral nutrition for promoting gastric emptying and tissue regeneration in patients is effective and safe [8] [10] [18]-[20].

The traditional care, which requires routine bed rest in the post-operative period, has no place in the enhanced recovery program. While immobility results in loss of muscles and fatigue. In order to prevent these problems effective and aggressive ambulation methods are used [15]. Patients' first post-operative mobilization durations are $33.67 \pm 19.53$ hours in average in this study. When the relation between the patients' first standing durations and the hospitalization durations was examined, it was found that post-operative hospitalization duration also extends as the first mobilization duration extends.

Another essential component for the enhanced recovery is to make an evidence-based decision in usage of traditional applications. It is also necessary to discuss the necessity of usage of tubes, drains and catheters and the duration of their stay. In case of an imperative usage the patient should be monitored closely and when the patient is ready it should be removed as soon as possible. In our study, it was approved that the levels of foley catheter and nasogastric application was low for they were applied to selected patients. The long-term application of these tubes may cause a limitation in mobility and irritation and in the end an increase in morbidity [2] [3].

\section{Conclusions}

Based on the study findings it was determined that some of the post-operative enhanced recovery applications were performed. It was also determined that as anesthesia method mostly general anesthesia was performed; pre- and post-operative fasting durations were not sufficiently limited; the first mobilization durations were long; total pain control could not achieved with the analgesics received by patients.

It can be suggested to enlighten the nurses about the initiation of attempts regarding the limitation of pre- and post-operative fasting durations; providing the patients with an earlier mobilization; usage of non-pharmacological analgesic methods.

Many areas of healthcare can be arranged to enhanced recovery. Enhanced recovery is an evidence based approach that aims to optimise outcomes and improve patients experiences.

\section{Source of Funding}

None.

\section{Declaration of Interest Disclosure}

Authors declare no conflicts of interest.

\section{References}

[1] Wilmore, W.D., Sawyer, F. and Kehlet, H. (2001) Management of Patients in Fast Track Surgery. British Medical Journal, 24, 473-476. http://dx.doi.org/10.1136/bmj.322.7284.473

[2] Pasero, C. and Belden, J. (2006) Evidence-Based Perianesthesia Care: Accelerated Postoperative Recovery Programs. Journal of Perianesthesia Nursing, 21, 168-176. http://dx.doi.org/10.1016/j.jopan.2006.03.010

[3] Mitchel, M. (2011) The Future of Surgical Nursing and Enhanced Recovery Programmes. British Journal of Nursing, 20, 978-984. http://dx.doi.org/10.12968/bjon.2011.20.16.978

[4] Kumar, A., Scholefield, J.H., Andersen, J. and Armitage, N.C. (2006) Fast Track Surgery. In: Johnson, C. and Taylor, I., Eds., Recent Advances in Surgery, Vol. 29, Ch. 5, RSM Press, London, 59-74.

[5] Kehlet, H. and Dahl, J.B. (2003) Anaesthesia, Surgery, and Challenges in Postoperative Recovery. Lancet, 362, 19211928. http://dx.doi.org/10.1016/S0140-6736(03)14966-5

[6] Sturm, L. and Cameron, A.L. (2009) Fast-Track Surgery and Enhanced Recovery after Surgery (ERAS) Programs. ASERNIP-S Report No. 74.

http://www.surgeons.org/media/299206/RPT_2009-12-09_Enhanced_Patient_Recovery_Programs.pdf 
[7] Kehlet, K. and Wilmore, D.W. (2008) Evidence-Based Surgical Care and the Evolution of Fast-Track Surgery. Annals of Surgery, 248, 189-198. http://dx.doi.org/10.1097/SLA.0b013e31817f2c1a

[8] Kuzma, J. (2008) Randomized Clinical Trial to Compare the Length of Hospital Stay and Morbidity for Early Feeding with Opioid-Sparing Analgesia Versus Traditional Care after Open Appendectomy. Clinical Nutrition, 27, 694-699. http://dx.doi.org/10.1016/j.clnu.2008.07.004

[9] Reismann, M., Mirja von Kampen, M.V., Laupichler, B., Suempelmann, R., Annika, I., Schmidt, A.I. and Ure, B.M. (2007) Fast-Track Surgery in Infants and Children. Journal of Pediatric Surgery, 42, 234-238. http://dx.doi.org/10.1016/j.jpedsurg.2006.09.022

[10] Terzioğlu, F., Şimsek, S., Karaca, K., Sariince, N., Altunsoy, P. and Salman, M.C. (2013) Multimodal Interventions (Chewing Gum, Early Oral Hydration and Early Mobilisation) on the Intestinal Motility Following Abdominal Gynaecologic Surgery. Journal of Clinical Nursing, 22, 9-10. http://dx.doi.org/10.1111/jocn.12172

[11] Harlak, A., Gündoğdu, H., Ersoy, E. and Erkek, B. (2008) Perspectives of the Surgeons in Ankara on the Post-Operative Enhanced Recovery (ERAS Protocol) Applications. Turkish Journal of Surgery, 24, 182-188.

[12] Çeçen, D., Koca Kutlu, A. and Y1lmaz, E. (2009) Analysis of the Surgical Patients' Hunger Situations in the PreOperative Period. In: Yavuz, M., Özbayır, T., Demir Korkmaz, F. and Kaymakçı, Ş., Eds., Turkish Surgical and Operating Room Nursing Congress, Congress Book, Kusadasi, 178-179.

[13] Ersoy, E. and Gündoğdu, H. (2005) Changing Theories in Post-Operative Hunger. Turkish Journal of Surgery, 21, 96101.

[14] Kitching, A.J. and O’Neill, S. (2009) Fast-Track Surgery and Anaesthesia. Continuing Education in Anaesthesia. Critical Care \& Pain, 9, 39-43. http://dx.doi.org/10.1093/bjaceaccp/mkp006

[15] Resolution ReSAP (2003) On Food and Nutritional Care in Hospitals (Adopted by the Committee of Ministers on 12 November 2003 at the 860th Meeting of the Ministers' Deputies). https://wcm.coe.int/ViewDoc.jzp?id=85747\&Lang=en

[16] Dolgun, E., Taşdemir, N., Ter, N. and Yavuz, M. (2011) Analysis of the Surgical Patient's Hunger Durations before the Operation. Firat University Medical Journal of Health Sciences Science Journal, 25, 11-15.

[17] (2005) Perioperative Fasting in Adults and Children. http://www.rcn.org.uk/_data/assets/pdf_file/0009/78678/002800.pdf

[18] Lewis, S.J., Egger, M., Sylvester, P.A. and Thomas, S. (2001) Early Enteral Feeding versus “Nil by Mouth” after Gastrointestinal Surgery: Systematic Review and Meta-Analysis of Controlled Trials. British Medical Journal, 323, 773-776. http://dx.doi.org/10.1136/bmj.323.7316.773

[19] Recel, J.R. and Segui, R.D. (2014) Early Oral Feeding after Appendectomy: A Prospective Study—Region I Medical Center. http://r1mc.doh.gov.ph/index.php/component/content/article/99

[20] Schulman, A.S. and Sawyer, R.G. (2005) Have You Passed Gas Yet? Time for a New Approach to Feeding Patients Postoperatively. Practical Gastroenterology Trition Issues in Gastroenterology, 32, 82. 


\section{Appendix}

\section{Data Collection Form}

\section{Part 1:}

Age: ......

Gender: Male ( ) Female( )

Education Level:.

Department: General Surgery ( ) Orthopedics ( ) Gynecology ( ) Urology ( ) Cardiovascular Surgery ( )

\section{Part 2:}

Obtained information about the operation: yes ( ) No ( ) If yes search of information: Dr ( ) Norse ( ) Both of them ( )

How did the nurse prepare you for the operation? Relieving Patients by Talking (providing psychological support) ( ) Dressing the Patients ( ) Taking off Patients' Accessories and Prosthesis ( ) Teaching the Patients Deep Breathing Coughing Exercises ( ) Teaching the Patients Extremity Exercises ( )

Preoperative thirstiness duration (hour):

Preoperative fasting duration (hour):

Postoperative first fluid intake (hour):

Postoperative first solid food intake (hour):

Postoperative first mobilization time: ...... hour $1^{\text {st }}$ day ( ) $2^{\text {nd }}$ day ( ) $3^{\text {rd }}$ day ( )

Anesthesia method: general ( ) spinal ( ) epidural ( )

Usage of tube, catheters: IV fluid intake ( ) foley catheter ( ) nasogastric tube ( )

Pain relief interventions: nonpharmacologic interventions: nsai ( ) pethidine ( ) tramadol ( ) paracetamol ( )

Nonpharmacologic interventions:

Postoperative length of stay at hospital (day:

Total length of stay at hospital (day): 